\title{
Work-related changes in peak expiratory flow among laboratory animal workers
}

\author{
A. Hollander, D. Heederik, B. Brunekreef
}

Work-related changes in peak expiratory flow among laboratory animal workers. A. Hollander, D. Heederik, B. Brunekreef. CERS Journals Ltd 1998.

ABSTRACT: Laboratory animal workers are at risk of developing allergic symptoms, of which asthmatic symptoms are the most severe. The aim was to study the relationship between allergic symptoms due to working with rats and variability and changes in peak expiratory flow (PEF).

Several indices were used on the basis of the amplitude of the PEF or the differences in PEF between days with and without exposure to rat aeroallergens. Of the 398 rat workers, $73 \%$ completed PEF readings on at least 9 days, of whom 208 had PEF readings on working days with and without contact with animals.

The overall prevalence rate of allergic symptoms (asthmatic, eye, nose and/or skin) among rat workers during the handling of rats was $17.3 \%$. Asthmatic symptoms were reported by $6.7 \%$. The PEF of the workers who reported asthmatic symptoms due to working with rats decreased significantly on days working with the animals (difference between the minimum PEF averaged over working days with animals and over days without animals $\left.(\triangle P E F \min -\mathrm{min})=-7.3 \mathrm{~L} \cdot \mathrm{min}^{-1}\right)$, compared to the workers without symptoms $\left(2.2 \mathrm{~L} \cdot \mathrm{min}^{-1}\right)$. This effect was more pronounced among workers with a late asthmatic response, i.e. the presence of asthmatic symptoms several hours after working with rats $\left(\triangle \mathrm{PEF}\right.$ min-min $\left.=-11.6 \mathrm{~L} \cdot \mathrm{min}^{-1}\right)$. Multiple regression analyses showed that only those with asthmatic symptoms several hours after working with rats and those with allergic symptoms had an increased $\triangle$ PEFmin-min. In addition, workers with asthmatic symptoms were also more likely to have a higher PEF variability than workers without asthmatic symptoms. However, no difference in PEF variability between days with and without animals contact was observed.

This study shows that the peak expiratory flow of workers who reported asthmatic symptoms due to working with rats decreased significantly on days working with laboratory animals.

Eur Respir J 1998; 11: 929-936.
Dept of Environmental Sciences, Environmental and Occupational Health Unit, Agricultural University Wageningen, The Netherlands

Correspondence: D. Heederik

Dept of Environmental Sciences

Environmental and Occupational Health

Group

Agricultural University Wageningen

P.O. Box 238

6700 AE Wageningen

The Netherlands

Fax: 31317485278

Keywords: Asthma

laboratory animals

occupational allergy

peak expiratory flow

Received: December 301996

Accepted after revision November 211997

This study was supported by research grants from the Netherlands Asthma Foundation, the Ministry of Social Affairs and Employment and the European Union (contract no. BMH1-CT94-1446)
Laboratory animal workers are at risk of developing work-related allergic asthma. Cross-sectional epidemiological studies among laboratory animal workers have reported prevalence rates of asthmatic symptoms, ranging 4-12\% [1-6]. Asthmatic symptoms are mostly accompanied by other respiratory symptoms and are considered as the end stage of laboratory animal allergy (LAA) $[2,4,5$, 7].

Occupational asthma can be demonstrated by recording the peak expiratory flow (PEF) several times a day on days away from and at work [8-11]. In clinical practice, several investigators have shown how visual inspection of PEF records can prove useful in identifying individuals with occupational asthma $[9,12]$. However, it is not clear to what extent monitoring of PEF is a useful tool to detect the presence of LAA in epidemiological surveys. In large-scale epidemiological studies the visual inspection of PEF records is not practical and a numerical expression of PEF variability or changes in PEF is to be preferred $[13,14]$. The amplitude percentage mean, defined as the daily maximal PEF minus the minimal PEF expressed as a percentage of the daily average, has been suggested as index of PEF variability [13]. This amplitude percentage mean has been applied in a limited number of occupational studies [15-17], in which it was shown to be associated with exposure to grain dust, polyvinylchloride and toluene diisocyanate. Serial PEF recording has also been used to study decline in PEF across work shifts in a population exposed to endotoxin [18]. However, none of these studies have used the differences in PEF variability or decline in PEF between days away from and at work as tools to study occupational asthma.

As part of a cross-sectional study among 540 laboratory animal workers $[6,19]$, the workers recorded their PEF over a period of about 2 weeks. This paper describes the PEF variability and changes in PEF and their relationships with allergic symptoms due to working with rats and sensitization to rat allergens. Several indices of PEF variability and changes in PEF were used, all focusing on the differences between days with and without exposure to rat urinary aeroallergens. In addition, we studied the associations between these indices and average levels of exposure to rat urinary aeroallergens, smoking, gender and atopy. 


\section{Materials and methods}

\section{Study population}

Employees from laboratory animal facilities of four universities, two research institutes, one pharmaceutical company and students of a laboratory school participated in the study. All subjects working with small laboratory animals or having contact with material from these animals were invited to participate. Of approximately 750 eligible subjects, 579 (77\%) participated. A completed questionnaire as well as skin-prick test (SPT) results were available for 540 participants [6]. Of these 540 participants, 398 $(74 \%)$ had recently been working with living rats (i.e. during the preceding 12 months) and were used in the analyses presented in this paper.

\section{Questionnaire}

The self-administered questionnaire contained questions about personal history of allergic symptoms due to common allergens, smoking history, occupational history and intensity of contact with laboratory animals [6]. In addition, questions were asked about the history of allergic symptoms due to working with rats during working hours as an indicator of an immediate response: "Do you have allergic symptoms during working hours, after contact with rats?". If a positive answer was given, questions were asked on type of symptoms (chest tightness (asthma), runny nose or sneezing, runny or itchy eyes and itchy or red skin). A similar question was asked with respect to symptoms occurring several hours after work as indicator of a late response: "Do you have allergic symptoms several hours after finishing work, due to contact with rats?". In this paper, having symptoms due to working with rats is defined as an immediate and/or late response, unless otherwise stated.

\section{Spirometry}

The forced vital capacity (FVC), forced expiratory volume in one second (FEV1) and PEF were measured with a dry rolling seal spirometer (Vicatest V; Jaeger, Breda, The Netherlands). Measurements were performed according to the lung function protocol of the European Community for Steel and Coal [20].

\section{PEF recording}

Each participant was given a mini-Wright peak flow meter and proper use of the meter was demonstrated immediately after administration of the questionnaire and performance of the spirometry. Participants were asked to record PEF during the 2 weeks following the medical survey. However, the diary could contain up to 20 days. Participants were asked to record PEF on four occasions during working days: on waking, at lunch time, just after the working day and at bedtime [21]. During weekends and holidays the participants had to record PEF on three occasions: on waking, at lunch time and at bedtime. On each occasion they were asked to blow, after maximal inspiration, three times into the peak flow meter and record all readings. Measurements were made in the standing position and the scale was read to the nearest scale mark $\left(5 \mathrm{~L} \cdot \mathrm{min}^{-1}\right)$. Contact with laboratory animals (yes/no) was recorded on each working day.

A day started with the first reading at work (after 09:30 h), continuing for the next $24 \mathrm{~h}$, so that the first reading after waking is included in the exposure period of the previous day [8]. The highest of the three attempts was used for analysis. All PEF records were plotted in two graphs to detect obvious data errors. The first graph showed the maximum, minimum and mean of each day's PEF values and the second graph showed the maximal PEF of each measurement. Of each individual series the first day was left out, because of the possibility of a learning effect. Only participants who had at least three readings per day for at least 9 days were used for the analyses presented in this paper. Several indices were used on the basis of the amplitude (Amp) of the PEF or the differences in PEF $(\triangle \mathrm{PEF})$ between working days with and without laboratory animal contact (fig. 1). The AMP was calculated for each day and averaged for weekend days (Ampweekend), working days without laboratory animal contact (Ampno animal) and working days with laboratory animal contact (Ampanimal). The difference between Ampanimal and the Ampno animal ( $\triangle \mathrm{Amp})$ was recorded. Furthermore, two different indices of change in PEF were used, the difference between the maximum PEF averaged over working days with animals and over days without animals ( $\triangle \mathrm{PEFmax}-$ $\max )$ and the difference between the respective minimum PEF values ( $\triangle \mathrm{PEFmin}$-min) (fig. 1). The indices were expressed in litres per minute. The indices expressed on the basis of the amplitude of the PEF were also expressed as a percentage of the daily mean (Amp\%mean).



Fig. 1. - Derivation of the various peak expiratory flow (PEF) indices used. Amp: amplitude; PEFmax: maximal PEF; PEFmin: minimal PEF; Ampno animal: Amp for PEF (PEFmax-PEFmin) on a working day without animal contact, averaged over all days; Ampanimal: Amp for PEF (PEFmax-PEFmin) on a working day with animal contact, averaged over all days; Ampweekend: Amp for PEF (PEFmax-PEFmin) on a weekend or holiday, averaged over all days; $\triangle$ Amp: Ampanimal-Ampno animal; $\triangle$ PEFmax-max: PEFmax averaged over all working days with animals; $\triangle$ PEFmin-min: PEFmin averaged over all working days with laboratory animals minus PEFmin averaged over all working days without animals. 


\section{Exposure assessment}

In order to estimate the exposure to rat urinary aeroallergens in the population of rat workers, personal full-shift inhalable dust was sampled and assayed on rat urinary allergen content by a sandwich enzyme immunoassay [22]. The dust samples were taken in a representative sample of 87 workers from all job titles and working zones. Each worker was sampled for 1 week on days when working with rats, resulting in a total of 251 personal full-shift airborne dust samples. On the basis of these measurements the zones were divided into three groups. The average rat urinary aeroallergen levels of these groups were combined with the hours working with rats per week as reported in the questionnaire, which resulted in an average "time-multiplied rat urinary aeroallergen exposure" for each worker [19]. Finally, the workers were grouped on the basis of their "time-multiplied rat urinary aeroallergen exposure".

\section{Skin-prick testing and immunoglobulin (Ig)E antibodies}

Five common aeroallergens (house dust mites, grass pollen, tree pollen, cat fur and dog fur), two occupational allergens (rat urine and rat fur) and positive (histamine 10 $\mathrm{mg} \cdot \mathrm{mL}^{-1}$, in duplicate) and negative controls (phosphatebuffered saline (PBS)) were used for skin-prick testing. In the sera, specific IgE antibodies to rat urinary aeroallergen were measured by immunoassay (AlaSTAT; DPC, Apeldoorn, the Netherlands) [6].

Sensitization to rat allergens was defined as a positive SPT response to rat urinary or rat fur allergens, and/or the presence of specific serum IgE antibodies to rat urinary allergens.

\section{Statistical analysis}

All statistical analyses were performed using Statistical Analysis System (SAS) software (version 6.09; SAS Inc., Cary, NC, USA). Prevalence rates were compared using either the $\chi^{2}$ or the Fisher's exact test. For testing group mean differences, Student's two-sample t-test was used. The distribution of the Amp and $\triangle \mathrm{PEF}$ indices were not clearly normally or log-normally distributed. Therefore, the median levels of these distributions were presented and group median differences were tested by using the nonparametric Wilcoxon rank-sum test for two levels.

Relationships between allergic symptoms due to working with rats, sensitization to rat allergens, average level of exposure to rat urinary aeroallergen and host factors and the PEF indices were studied by linear multiple regression analyses.

\section{Results}

Of the 398 rat workers, $289(73 \%)$ completed PEF readings on at least 9 days. In this group of workers, the average number of days was 13, range 9-19 days. Seventy one workers $(18 \%)$ returned an incomplete diary and 38 $(10 \%)$ did not return their diary at all. The workers for whom no properly completed PEF record was available were significantly younger (table 1). These workers also smoked more often and reported more allergic symptoms due to working with rats. However, these differences were not statistically significant. In addition, table 1 shows a large difference between the Ampweekend and Ampno animal. This difference might be attributed to differences in time of the first measurements, which on working days occurred on average at 07:50 h and on weekends at 09:30 h. We therefore used only the PEF readings on working days with and without animal contact in all further analyses. Two hundred and eight rat workers had PEF readings on both working days with and without animal contact (table 1). Among these workers, the prevalence rates of sensitization to rat allergen and the prevalence rate of allergic symptoms (asthmatic, eye, nose and/or skin) during or after working with rats were $18.4 \%$ and $17.3 \%$, respectively. Thirteen per cent of the rat workers were both sensitized and symptomatic. Asthmatic symptoms during or after handling rats was reported by $6.7 \%$ of the workers. Of these workers with asthmatic symptoms, $86 \%$ were sensitized to rat allergens.

Table 1. - Characteristics of rat workers, stratified by PEF readings

\begin{tabular}{|c|c|c|c|}
\hline & \multicolumn{2}{|c|}{ PEF readings } & \multirow{2}{*}{$\begin{array}{l}\text { PEF readings on working days } \\
\text { with and without animal contact }\end{array}$} \\
\hline & No & Yes & \\
\hline Subjects $n$ & 109 & 289 & 208 \\
\hline Females \% & 34.9 & 38.4 & 42.8 \\
\hline Age yrs $^{+}$ & $32.5(9.7)$ & $35.3(9.6) *$ & $34.6 \pm 9.3$ \\
\hline Current smokers \% & 35.8 & 26.4 & $24.6^{\dagger}$ \\
\hline Allergic symptoms due to rats $\%$ & 25.7 & 17.3 & 17.3 \\
\hline Sensitized to rat allergens $\%$ & $17.6^{\dagger}$ & $17.7^{\dagger}$ & $18.4^{\dagger}$ \\
\hline Rat allergy $\%$ & $15.7^{\dagger}$ & $12.5^{\dagger}$ & $13.0^{\dagger}$ \\
\hline \multicolumn{4}{|l|}{ PEF variability, median in $\mathrm{L} \cdot \mathrm{min}^{-1}$} \\
\hline Ampweekend & & $25.0 \quad(n=282)$ & $25.0 \quad(n=204)$ \\
\hline Ampno animal & & $30.0(n=256)$ & $30.0 \quad(n=208)$ \\
\hline Ampanimal & & $30.0(n=241)$ & $29.6(n=208)$ \\
\hline \multicolumn{4}{|l|}{ Spirometry $\%$ pred } \\
\hline FVC & $102(n=108)$ & $104(n=285)$ & $103(n=205)$ \\
\hline FEV1 & $101 \quad(n=108)$ & $101 \quad(n=285)$ & $100(n=205)$ \\
\hline PEF & $113(n=108)$ & $112(\mathrm{n}=285)$ & $111(n=205)$ \\
\hline
\end{tabular}

*: $\mathrm{p}<0.05$ versus workers with no PEF readings; ${ }^{\dagger}$ : one observation was missing; + : allergic symptoms due to working with rats and sensitized to rat allergens; +: mean (SD). FVC: forced vital capacity; FEV1: forced expiratory volume in one second. For further definitions of abbreviations, see figure 1 . 
The PEF indices, stratified by sensitization to rat allergens or allergic symptoms due to working with rats, are presented in table 2. Both Ampno animal and Ampanimal were significantly higher for sensitized rat workers compared to nonsensitized workers. However, the amplitudes did not differ between working days with and without animal contact $(\triangle \mathrm{Amp}=0)$. Similar, but nonsignificant results were found for the Amp\%mean with no animal contact and Amp\%mean with animal contact. More contrast in the indices of PEF variability was found after stratifying for allergic symptoms due to rat allergens (table 2). The Ampno animal and Ampanimal were both significantly higher for rat workers with asthmatic symptoms due to working with rats, compared to workers without symptoms. The amplitudes of workers with other allergic symptoms (i.e. nose, eye or skin symptoms) were only slightly higher compared to the amplitudes of the workers without symptoms. The $\Delta \mathrm{Amp}$ was higher for workers with asthmatic symptoms compared to the other workers. However, these differences were not statistically significant.

The $\triangle$ PEFmin-min and $\triangle$ PEFmax-max were both significantly decreased among the workers with asthmatic symptoms compared to the other workers (table 2). The $\triangle$ PEFmin-min and $\triangle$ PEFmax-max of the workers with asthmatic symptoms were decreased by a similar magnitude (-7.3 and $-6.7 \mathrm{~L} \cdot \mathrm{min}^{-1}$, respectively). The indices presented in table 2 suggest that among the workers with asthmatic symptoms, the mean PEF was lower but the mean amplitude was similar on working days with laboratory animal contact compared with working days without animal contact. Despite the significant differences of the median values of the various indices between groups, the variation of the indices is large within each of these groups (fig. 2).

Of the 14 workers with asthmatic symptoms, 10 reported asthmatic symptoms several hours after working with rats, which was used as an indicator of a late asthmatic response. The indices of PEF variability (Ampno animal $=$ $39.2 \mathrm{~L} \cdot \mathrm{min}^{-1}$, Ampanimal $=37.0 \mathrm{~L} \cdot \mathrm{min}^{-1}$ ) and indices of changes in PEF $\left(\triangle \mathrm{PEFmin}-\mathrm{min}=-11.6 \mathrm{~L} \cdot \mathrm{min}^{-1}, \Delta \mathrm{PEFmax}-\right.$ $\left.\max =-10.9 \mathrm{~L} \cdot \mathrm{min}^{-1}\right)$ were all higher and lower, respectively, compared to the values presented in table 2 , suggest-
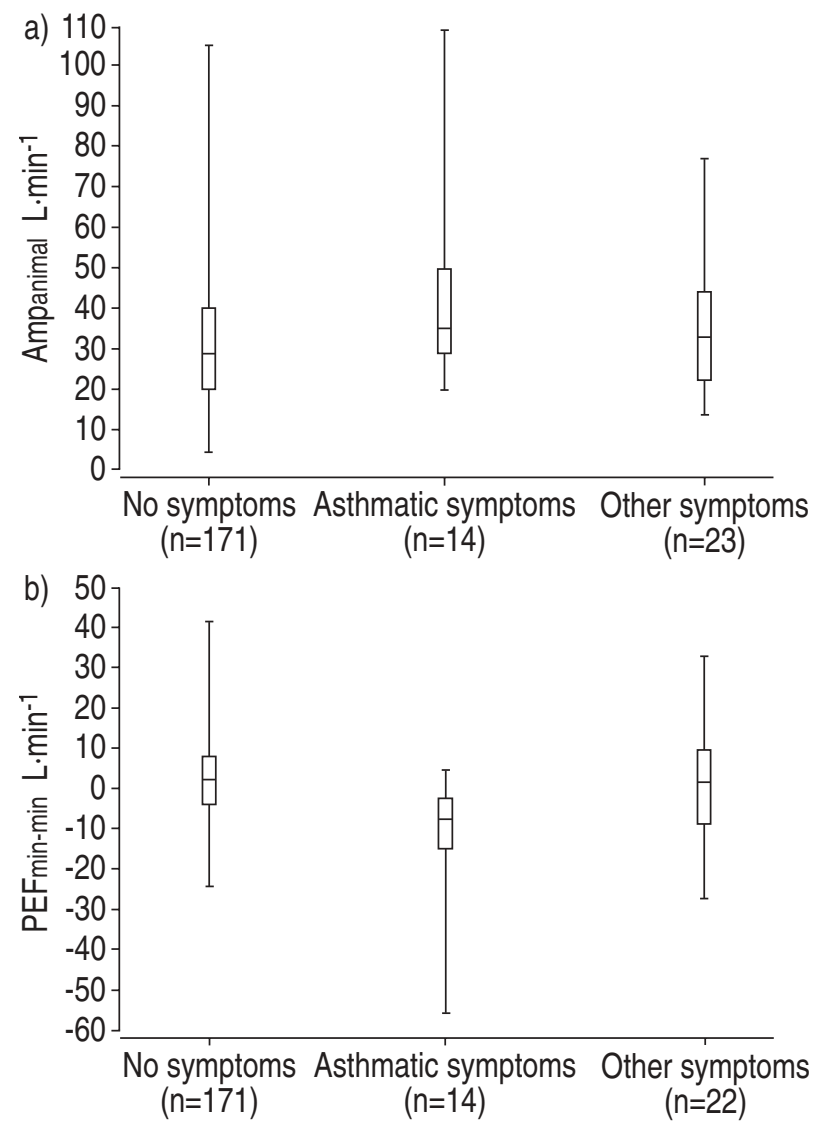

Fig. 2. - Median (centre of box), 25th and 75th percentiles (borders of box) and range (whiskers) for: a) Ampanimal ( $n=208)$; and b) $\triangle$ PEFmin$\min (n=207$ one value was not plotted because of a very high level), stratified according to allergic symptoms due to working with rats ( $\mathrm{n}=$ 208). For definitions of abbreviations, see legend to figure 1.

ing more pronounced effects on PEF in workers with a late asthmatic response.

Table 3 shows the associations between the PEF indices and average exposure level to rat urinary aeroallergens, and several host factors. Ampno animal and Ampanimal were significantly elevated among workers in the group with high average rat urinary aeroallergens exposure compared

Table 2. - The PEF indices stratified by sensitization to rat allergens and allergic symptoms (asthmatic, eye, nose and/or skin) due to working with rats

\begin{tabular}{|c|c|c|c|c|c|}
\hline & \multicolumn{2}{|c|}{ Sensitization to rat allergens ${ }^{\dagger}$} & \multicolumn{3}{|c|}{ Symptoms due to working with rats } \\
\hline & No & Yes & No & Asthmatic symptoms & Other \\
\hline Subjects $n$ & 169 & 38 & 171 & 14 & 23 \\
\hline PEF $\mathrm{L} \cdot \mathrm{min}^{-1+}$ & $550 \pm 96$ & $587 \pm 89$ & $549 \pm 97$ & $544 \pm 97$ & $613 \pm 77 \#$ \\
\hline Working days without animal contact $\mathrm{n}^{+}$ & $4.4 \pm 2.6$ & $4.3 \pm 3.2$ & $4.5 \pm 2.7$ & $3.5 \pm 2.3$ & $4.1 \pm 3.2$ \\
\hline Working days with animal contact $\mathrm{n}^{+}$ & $5.6 \pm 3.2$ & $5.7 \pm 3.3$ & $5.5 \pm 3.3$ & $5.8 \pm 2.4$ & $6.3 \pm 3.4$ \\
\hline \multicolumn{6}{|l|}{ Indices of PEF variability\$ } \\
\hline Ampno animal $\mathrm{L} \cdot \mathrm{min}^{-1}$ & 28.0 & $33.2^{\S}$ & 29.0 & $35.3^{\ddagger}$ & 30.0 \\
\hline Ampanimal $\quad L \cdot \min ^{-1}$ & 29.0 & 35.2 & 28.8 & $35.2 \ddagger$ & 33.3 \\
\hline $\mathrm{L} \cdot \mathrm{min}^{-1}$ & 0 & 0 & -0.24 & 3.5 & 0 \\
\hline Amp\%mean No animal contact & 5.2 & 5.9 & 5.3 & 7.5 & $4.9 * *$ \\
\hline Animal contact & 5.1 & 5.6 & 5.1 & 5.9 & 5.8 \\
\hline \multicolumn{6}{|l|}{ Indices of changes in PEF\$ } \\
\hline$\Delta \mathrm{PEFmax}^{\mathrm{max}} \mathrm{L} \cdot \mathrm{min}^{-1}$ & 2.5 & -2.4 & 2.5 & $-6.7 \S$ & $1.7 *$ \\
\hline$\Delta$ PEFmin-min $\quad \mathrm{L} \cdot \mathrm{min}^{-1}$ & 1.9 & -0.71 & 2.2 & $-7.3^{\S}$ & $4.0^{*}$ \\
\hline
\end{tabular}

†: one observation missing; +: mean \pm sD; $\$$ : median; $\$: p<0.01$ (one-tailed) versus nonsensitized group or group with no symptoms; \#: $\mathrm{p}<0.05$ compared to group with no symptoms and the group with asthmatic symptoms; $\sharp \mathrm{p}<0.05$ (one-tailed) compared to the nonsensitized group or the group with no symptoms; ***: $\mathrm{p}<0.05, \mathrm{p}<0.01$ (one-tailed) versus group with asthmatic symptoms. For definition of abbreviations, see legend to figure 1 . 
Table 3. - Separate analyses of the associations between the PEF indices and average level of exposure to rat urinary aeroallergens, and various host factors $(n=208)$

\begin{tabular}{|c|c|c|c|c|c|c|}
\hline & $\begin{array}{l}\text { Subjects } \\
n\end{array}$ & $\begin{array}{c}\text { Ampno animal } \\
\mathrm{L} \cdot \mathrm{min}^{-1}\end{array}$ & $\underset{\mathrm{L} \cdot \mathrm{min}^{-1}}{\text { Ampanimal }}$ & $\begin{array}{l}\Delta \mathrm{Amp} \\
\mathrm{L} \cdot \mathrm{min}^{-1}\end{array}$ & $\begin{array}{l}\Delta \mathrm{PEF} \max ^{-m a x} \$ \\
\mathrm{~L} \cdot \mathrm{min}^{-1}\end{array}$ & $\begin{array}{c}\Delta \mathrm{PEFmin}-\min ^{\$} \\
\mathrm{~L} \cdot \mathrm{min}^{-1}\end{array}$ \\
\hline \multicolumn{7}{|l|}{ Average rat urinary aeroallergen } \\
\hline Low & 70 & 28.6 & 28.5 & -0.83 & 1.7 & 2.0 \\
\hline Medium & 75 & 27.5 & 27.5 & 0.83 & 2.0 & 0.75 \\
\hline High & 63 & 30.0 *\# & $34.2 *$ & 0 & 1.7 & 2.7 \\
\hline \multicolumn{7}{|l|}{ Smoking ${ }^{\dagger}$} \\
\hline No & 156 & 27.4 & 28.8 & 0.83 & 2.0 & 1.9 \\
\hline Yes & 51 & $34.0 * *$ & 33.6 & -1.3 & 0 & 0.17 \\
\hline SPT- to all five common allergens & 126 & 27.3 & 27.9 & -0.23 & 2.4 & 1.1 \\
\hline SPT+ to cat and/or dog fur & 51 & $35.0 * *$ & $34.4 *$ & 0 & 0 & 1.9 \\
\hline SPT+, but SPT+ to both cat and dog fur & 31 & $27.5^{\#}$ & 27.5 & 1.5 & 3.3 & 2.7 \\
\hline $\begin{array}{l}\text { No history of allergic symptoms to } \\
\text { common allergens }\end{array}$ & 149 & 28.0 & 28.9 & 0 & 2.5 & 2.3 \\
\hline Allergic symptoms to pets & 23 & 30.0 & 31.1 & 2.9 & -0.83 & $-5.0^{*}$ \\
\hline Symptoms to common allergens, but not to pets & 36 & 31.7 & 34.4 & 0.42 & 0 & $1.6^{\#}$ \\
\hline
\end{tabular}

s: median values; *,**: $\mathrm{p}<0.05, \mathrm{p}<0.01$ (one-tailed) versus "No" or first group; \#: $\mathrm{p}<0.05$ (one-tailed) versus medium exposure group, or group with SPT+ to cat and/or dog fur, or the group with allergic symptoms to pets; ${ }^{\dagger}$ : one observation missing. SPT: skin-prick test; +: positive; -: negative. For further definitions of abbreviations, see legend to figure 1.

to these indices among the workers in the low exposure group. No effect of the average level of exposure was found on the $\triangle \mathrm{Amp}$ and $\triangle \mathrm{PEF}$ indices. The Ampno animal and Ampanimal were both elevated for smokers $(34.0$ and $33.6 \mathrm{~L} \cdot \mathrm{min}^{-1}$ for smokers and 27.4 and $28.8 \mathrm{~L} \cdot \mathrm{min}^{-1}$ for nonsmokers). However, this difference was statistically significant only for the Ampno animal. Again, no effect was found on the $\triangle \mathrm{AMP}$ and $\triangle \mathrm{PEF}$ indices. Of the host factors related to atopy, a positive SPT reaction to at least one of the five common allergens was significantly associated with Ampno animal and Ampanimal. These differences were larger when only the SPT responses to cat and dog fur were taken into account (35.0 and $34.4 \mathrm{~L} \cdot \mathrm{min}^{-1}$; table 3). Among workers with positive SPT responses to grass pollen, tree pollen or house dust mite allergens, but negative SPT responses to cat and dog fur, these indices were similar (both 27.5) to those among workers with no response to any common allergen $\left(27.3\right.$ and $27.9 \mathrm{~L} \cdot \mathrm{min}^{-1}$, respectively). Similar, but less pronounced, results were found for personal history of allergic symptoms to common allergens as reported in the questionnaire. On the other hand, workers with allergic symptoms to pets had a significantly decreased $\triangle \mathrm{PEFmin}$-min when compared to all other workers (table 3 ). Of the workers with allergic symptoms to pets, the $\triangle \mathrm{PEFmin}$-min was more decreased among workers who were also sensitized to rat allergens, -8.8 L·min ${ }^{-1}$, compared to $-2.8 \mathrm{~L} \cdot \mathrm{min}^{-1}$ for nonsensitized workers. Of the PEF indices presented in table 3, none were associated with gender, age, height or mean PEF. However, the Amp\%mean indices were all associated with age, gender, height and average PEF, which suggests that presenting the Amp as a percentage of its daily mean introduced correlations with variables related to the average PEF. Therefore, in table 3 and in the remaining part of this paper only the absolute values, in litres per minute, are presented.

The variables presented in tables 2 and 3 were used in multiple regression analyses with the PEF indices as dependent variables (table 4). Sensitization to rat allergens, symptoms due to working with rats, average level of exposure to rat urinary aeroallergens and several host factors explained less than $12 \%$ of the variation of the indices. Similar to the results presented in table 2 and 3, the variables tested resulted in an increase in Ampno animal as well as in Ampanimal. However, of all variables tested only an SPT-positive response to cat and/or dog fur was significantly associated with Ampno animal. In contrast, asthmatic symptoms due to rat allergens several hours after working with rats was strongly associated with the $\triangle \mathrm{PEF}$ indices. All other variables showed no relationship with the $\triangle \mathrm{PEF}$ indices, except for the presence of allergic symptoms to pets, which was associated with a decrease in $\triangle$ PEFmin-min.

Table 4. - Regression coefficients and standard errors of multiple regression analyses with the PEF indices as dependent variable and sensitization, allergic symptoms, exposure level and various host factors as independent variables $(n=205)$

\begin{tabular}{|c|c|c|c|c|c|c|}
\hline \multirow[b]{3}{*}{$\overline{\mathrm{r}^{2} \%}$} & \multicolumn{6}{|c|}{ Regression coefficients (SE) of various indices of PEF variability } \\
\hline & Ampno animal & \multirow{2}{*}{$\begin{array}{l}\text { Ampanimal } \\
7.5\end{array}$} & \multicolumn{2}{|c|}{$\Delta$ PEFmax-max } & \multicolumn{2}{|c|}{$\Delta \mathrm{PEF}$ min-min } \\
\hline & 9.9 & & 8.7 & & 11.1 & \\
\hline Constant & $27.0(1.5)^{* *}$ & $29.0(1.6)^{* *}$ & 4.7 & $(1.3)^{* *}$ & 2.6 & $(1.1)^{* *}$ \\
\hline Asthmatic symptoms several $\mathrm{h}$ after working with rats & $6.8(5.4)$ & $6.8(5.9)$ & -16.0 & $(4.6)^{* *}$ & -16.0 & $(4.1)^{* *}$ \\
\hline Sensitization to rat allergens & $1.6(3.3)$ & $4.3(3.6)$ & 1.9 & $(2.8)$ & -0.87 & $(2.5)$ \\
\hline Exposure to rat urinary aeroallergens, high versus medium/low & $3.4(2.4)$ & $2.1(2.6)$ & -0.63 & $(2.0)$ & 0.63 & $(1.8)$ \\
\hline Smoking & $3.6(2.5)$ & $1.9(2.8)$ & -2.3 & (2.1) & -0.60 & (1.9) \\
\hline SPT+ to cat or dog fur & $6.9(2.8)^{* *}$ & $4.7(3.1)$ & -1.0 & $(2.4)$ & 1.2 & $(2.2)$ \\
\hline Allergic symptoms to pets & $2.2(3.5)$ & $3.3(3.8)$ & -3.9 & (2.9) & -5.0 & $(2.6)^{*}$ \\
\hline
\end{tabular}

Three workers were excluded because blood samples or information on smoking habits were missing or because of outlying variables $*, * *: p<0.05, p<0.01$ (one-tailed). SPT+: skin-prick test positive. For further definitions of abbreviations, see legend to figure 1. 


\section{Discussion}

This study shows that the PEF of workers who reported asthmatic symptoms due to working with rats decreased significantly on days when they worked with laboratory animals. This effect was more pronounced among workers with a late asthmatic response, i.e. the presence of asthmatic symptoms several hours after working with rats. In addition, workers with asthmatic symptoms were also more likely to have a higher PEF variability than workers without asthmatic symptoms, even if these workers without asthmatic symptoms experienced skin, eye or nose symptoms due to working with rats. However, no difference in PEF variability between days with and without contact with laboratory animals was observed.

Variation of PEF in time has shown to be a useful marker of reversible airway obstruction due to exposure to environmental hazards. In epidemiological studies, a numerical expression of the PEF variability or change in PEF is most often used. Of the various proposed indices of PEF variability [13, 23-26], the Amp\%mean discriminated best between subjects with and without asthma [13]. However, our study showed that the Amp\%mean was associated with age, gender, height and average PEF. This suggested that correction of Amp for mean PEF introduced correlations with other variables. This effect could also be present in other studies in which associations between Amp\%mean and gender [24, 27], age [28, 29] or mean PEF [29] have been found. Therefore, we preferred to use the absolute values, in litres per minute, in our study.

In this study several indices of PEF variability and changes in PEF were used. Of these indices, $\triangle \mathrm{Amp}$ and $\triangle \mathrm{PEF}$ describe differences in PEF between days with and without exposure, i.e. contact with laboratory animals. The effect of exposure on the PEF variability has been studied in several occupational studies [15-17]. Two of these studies $[16,17]$ found a relationship between exposure to occupational agents and PEF variability, but these studies did not differentiate between days away from and at work. In our study the amplitude of the PEF was significantly elevated for the workers with asthmatic symptoms due to working with rats compared to the workers without symptoms. However, the amplitude was elevated on working days with as well as without contact with laboratory animals (table 2). In contrast, exposure had an effect on the level of the PEF among workers with asthmatic symptoms due to working with rats. These workers showed a statistically significant work-related dip in PEF (i.e. decreased $\triangle \mathrm{PEFmax}-\max \left(-6.7 \mathrm{~L} \cdot \mathrm{min}^{-1}\right)$ and $\triangle \mathrm{PEFmin}-$ min $\left(-7.3 \mathrm{~L} \cdot \mathrm{min}^{-1}\right)$; table 2$)$. The magnitude of the workrelated dip however, is, small compared to the mean PEF $(1.3 \%)$

A work-related decrease in PEF was strongly associated with the presence of asthmatic symptoms several hours after working with rats. Interestingly, of all other possible determinants of the $\triangle \mathrm{PEFmin}$-min, such as average level of exposure to rat urinary aeroallergen, smoking, gender and atopy, only the presence of allergic symptoms to pets was associated with $\triangle P E F m i n-m i n$. Of the workers with allergic symptoms to pets, those who were also sensitized to rat allergens, showed the largest work-related decrease in PEF. In previous analyses of data from the same population, we found that allergy to pets was a risk factor for sensitization to rat allergens [6]. However, not all sensi- tized workers reported symptoms. It is, therefore, possible that sensitized workers had not (yet) reported chest symptoms due to rat allergens, while at the same time a small work-related decrease in PEF could be detected.

On each day, the participant had to report working with laboratory animals (yes/no). No information was available on the number of hours spent working with rats or the actual rat urinary aeroallergen exposure on each day of measurement. Besides this crude daily measure of exposure, the average level of rat urinary aeroallergen exposure was used as an estimate of the daily exposure. However, this estimate of exposure could not be related to a decrease in PEF. As described elsewhere, there is a high variability of exposure from day to day for each worker $[19,22]$ and this could account for the fact that a relationship between increasing level of average exposure and decrease in PEF was not found. In order to relate changes in PEF with level of exposure to rat urinary aeroallergen, it is probably necessary to measure the exposure repeatedly as well. This approach was performed in a study among workers exposed to fuel oil ash [30].

Several potential biases may have influenced the results. During PEF measurements learning effects can be present $[25,29]$. In the present study these effects were minimized by leaving the first day of the measurement period out of the analysis. Further analyses of the data showed no relationship between day of measurement and maximum, minimum and average PEF. Furthermore, workers can falsify their PEF measurements [31-33] or data errors can occur. Therefore, the graphs of all records were visually inspected. Irregularities were only found during the first day of some of the records, which is in agreement with the possibility of a learning effect. No further irregularities were found in the graphs, probably due to the fact that workers who were not motivated probably failed to return a properly completed PEF record $(n=109)$ and were, therefore, not included in the analyses.

Study design may also have influenced the results. Firstly, the PEF variability is reduced when the number of daily measurements is reduced $[21,34]$. However, reducing the number of daily measurements decreases the sensitivity, but has little effect on the specificity in order to distinguish between responders and nonresponders [34]. Secondly, the time of measurement is very important. Workers may fail to record the lowest PEF, which is normally present in the morning, when they do not need to get up early, as on weekends or on holiday [35]. Therefore, we only used results on working days in our analyses in order to minimize these problems. However, using only working days could underestimate the differences found between working days with and without contact with laboratory animals. Despite the fact that in most laboratory animal facilities the animal rooms were separated from the nonanimal rooms or were even in other buildings, there is still a possibility of a small allergen exposure due to contaminated clothing or the ventilation system. Thirdly, of the 208 rat workers, 162 reported that they were also working with mice. Of these workers, 13 had symptoms due to working with mice, of whom 10 were also having symptoms due to rats. Exposure to mouse allergens could not explain an increased PEF variability in the absence of exposure to rats, because the PEFno animal also means that there was no contact with mice. It is possible, however, 
that workers with symptoms due to mice might have an increased PEF variability. However, this group is very small $(n=3)$ compared to the large group of rat workers without symptoms $(n=171)$ and would, therefore, hardly have changed the values presented for this group if the workers with symptoms due mice were left out. Finally, the workers had to record their PEF for 2 weeks, irres-pective of the exposure. Due to this study design, 81 of the 289 rat workers had no data on working days with or on working days without exposure to laboratory animals. In addition, of the 208 remaining workers 110 workers had data on less than 3 days with exposure or without exposure. As a result, these four effects of study design may influence the precision of the estimate of a worker's PEF index, but will not have altered the findings in this paper.

In conclusion, this study shows that serial peak expiratory flow measurements can be useful in detecting shortterm responses to an occupational exposure. However, there was a high variation in the level of changes in peak expiratory flow between workers and only a small part of this variation could be explained by known factors. This may limit the role of serial peak expiratory flow measurements in epidemiological studies on occupational asthma. However, further study on the useability of serial peak expiratory flow measurements in occupational epidemiological studies is warranted.

Acknowledgements: The authors wish to thank J. Spithoven and S. de Wind for their technical assistance and all laboratory animal workers for their participation.

\section{References}

1. Schumacher MJ, Tait BD, Holmes MC. Allergy to murine antigens in a biological research institute. J Allergy Clin Immunol 1981; 68: 310-318.

2. Cockcroft A, Edwards J, McCarthy P, Andersson N. Allergy in laboratory animal workers. Lancet 1981; 1: 827-830.

3. Beeson MF, Dewdney JM, Edwards RG, Lee D, Orr RG. Prevalence and diagnosis of laboratory animal allergy. Clin Allergy 1983; 13: 433-442.

4. Venables KM, Tee RD, Hawkins ER, et al. Laboratory animal allergy in a pharmaceutical company. $\mathrm{Br} J$ Ind Med 1988; 45: 660-666.

5. Cullinan P, Lowson D, Nieuwenhuijsen MJ, et al. Work related symptoms, sensitisation, and estimated exposure in workers not previously exposed to laboratory rats. Occup Environ Med 1994; 51: 589-592.

6. Hollander A, Doekes G, Heederik D. Cat and dog allergy and total $\operatorname{IgE}$ as risk factors of laboratory animal allergy. $J$ Allergy Clin Immunol 1996; 98: 545-554.

7. Aoyama K, Ueda A, Manda F, Matsushita T, Ueda T, Yamauchi C. Allergy to laboratory animals: an epidemiological study. Br J Ind Med 1992; 49: 41-47.

8. Burge PS. Diagnosis of occupational asthma. Clin Exp Allergy 1989; 19: 649-652.

9. Burge PS. Use of serial measurements of peak flow in the diagnosis of occupational asthma. In: Eisen AE, ed. Occupational Medicine: Spirometry (vol. 8). Philadelphia, Hanley and Belfus, Inc., 1993; pp. 279-294.

10. Moscato G, Godnic-Cvar J, Maestrelli P. Statement on self-monitoring of peak expiratory flows in the investigation of occupational asthma. Eur Respir J 1995; 8: 1605-
1610.

11. Cartier A. Definition and diagnosis of occupational asthma. Eur Respir J 1994; 7: 153-160.

12. Venables KM, Burge PS, Davison AG, Newman Taylor AJ. Peak flow rate records in surveys: reproducibility of observers' reports. Thorax 1984; 39: 828-832.

13. Higgins BG, Britton JR, Chinn S, et al. The distribution of peak expiratory flow variability in a population sample. Am Rev Respir Dis 1989; 140: 1368-1372.

14. Eisen EA, Wegman DH, Kriebel D. Application of peak expiratory flow in epidemiologic studies of occupation. In: Eisen EA, eds. Occupational Medicine: Spirometry (vol 8; no 2). Philadelphia, Hanley and Belfus, Inc., 1993; pp. 265-277.

15. Revsbech P, Andersen G. Diurnal variation in peak expiratory flow rate among grain elevator workers. $\mathrm{Br} J$ Ind Med 1989; 46: 566-569.

16. Lee HS, Ng TP, Ng YL, Phoon WH. Diurnal variation in peak expiratory flow rate among polyvinylchloride compounding workers. Br J Ind Med 1991; 48: 275-278.

17. Lee HS, Phoon WH. Diurnal variation in peak expiratory flow rate among workers exposed to toluene diisocyanate in the polyurethane foam manufacturing industry. $\mathrm{Br} \mathrm{J}$ Ind Med 1992; 49: 423-427.

18. Milton DK, Wypÿ D, Kriebel D, Walters MD, Hammond SK, Evans JS. Endotoxin exposure-repsonse in a fiberglass manufacturing facility. Am J Ind Med 1996; 29: 313.

19. Hollander A, Heederik D, Doekes G. Respiratory allergy to rats: exposure-response relationships in laboratory animal workers. Am J Respir Crit Care Med 1997; 155: 562 567.

20. Quanjer PH, Tammeling GJ, Cotes JE, Pedersen OF, Peslin R, Yernault JC. Lung volumes and forced ventilatory flows. Report working party standardization of lung function tests European Community for Steel and Coal. Official statement of the European Respiratory Society. Eur Respir J 1993; 6, Suppl 16: 5-40.

21. Malo JL, Coté J, Cartier A, Boulet LP, L'Archevêque J, Chan-Yeung M. How many times per day should peak expiratory flow rates be assessed when investigating occupational asthma? Thorax 1993; 48: 1211-1217.

22. Hollander A, van Run P, Spithoven J, Doekes G, Heederik D. Exposure of laboratory animal workers to airborne rat and mouse urinary allergens. Clin Exp Allergy 1997; 27: 617-626.

23. Hetzel MR, Clark TJH. Comparison of normal and asthmatic circadian rhythms in peak expiratory flow rate. Thorax 1980; 35: 732-738.

24. Boezen HM, Schouten JP, Postma DS, Rijcken B. Relation between respiratory symptoms, pulmonary function and peak flow variability in adults. Thorax 1995; 50: 121-126.

25. Quackenboss JJ, Lebowitz MD, Kryzanowski M. The normal range of diurnal changes in peak flow expiratory flow rates: relationship to symptoms and respiratory disease. Am Rev Respir Dis 1991; 143: 323-330.

26. Reddel HK, Salome CM, Peat JK, Woolcock AJ. Which index of peak expiratory flow is most useful in the management of stable asthma? Am J Respir Crit Care Med 1995; 151: 1320-1325.

27. Boezen HM, Postma DS, Schouten JP, Kerstjens AM, Rijcken B. PEF variability, bronchial responsiveness and their relation to allergy markers in a random population (20-70 yr). Am J Respir Crit Care Med 1996; 154: 3035 .

28. Higgins BG, Britton JR, Chinn S, Cooper S, Burney PGJ, 
Tattersfield E. Comparison of bronchial reactivity and peak expiratory flow variability measurements for epidemiologic studies. Am Rev Respir Dis 1992; 145: 588-593.

29. Neukirch F, Liard R, Segala C, Korobaeff M, Henry $\mathrm{C}$, Cooreman J. Peak expiratory flow variability and bronchial responsiveness to methacholine: an epidemiologic study in 117 workers. Am Rev Respir Dis 1992; 146: 7175.

30. Hauser R, Daskalakis C, Christiani DC. A regression approach to the analysis of serial peak flow among fuel oil ash exposed workers. Am J Respir Crit Care Med 1996; 154: 974-980.

31. Malo JL, Trudeau C, Ghezzo H, L'Archevêque J, Cartier A. Do subjects investigated for occupational asthma through serial peak expiratory flow measurements falsify their results? J Allergy Clin Immunol 1995; 96: 601-607.

32. Hyland ME, Kenyon CAP, Allen R, Howarth P. Diary keeping in asthma: comparison of written and electronic methods. BMJ 1993; 306: 487-489.

33. Quirce S, Contreras G, Dybuncio A, Chan-Yeung M. Peak expiratory flow monitoring is not a reliable method for establishing the diagnosis of occupational asthma. Am J Respir Crit Care Med 1995; 152: 1100-1102.

34. Zureik M, Liard R, Ségala C, Henry C, Korobaeff M, Neukirch F. Peak expiratory flow rate variability in population surveys: does the number of assessments matter? Chest 1995; 107: 418-423.

35. Venables KM, Davison AG, Browne K, Newman Taylor AJ. Pseudo-occupational asthma. Thorax 1989; 44: 760761. 